\title{
Changing attitudes toward redistribution: The role of perceived economic inequality in everyday life and intolerance of inequality
}

\author{
Juan Diego García-Castro \\ Sede de Occidente, Universidad de Costa Rica, San Ramón, Costa Rica \\ Centro de Estudios de Conflicto y Cohesión Social (COES), Chile \\ Corresponding author: juandiego.garcia@ucr.ac.cr \\ Roberto González \\ Escuela de Psicología, Pontificia Universidad Católica de Chile, Santiago, Chile \\ Cristián Frigolett \\ Escuela de Psicología, Pontificia Universidad Católica de Chile, Santiago, Chile \\ Gloría Jiménez-Moya \\ Escuela de Psicología, Pontificia Universidad Católica de Chile, Santiago, Chile \\ Rosa Rodríguez-Bailón \\ Universidad de Granada, Centro de Investigación Mente Cerebro y Comportamiento, \\ Granada, España \\ Guillermo B. Willis \\ Universidad de Granada, Centro de Investigación Mente Cerebro y Comportamiento, \\ Granada, España
}

\section{How to cite this paper:}

García-Castro, J.D., González, R., Frigolett, C., Jiménez-Moya, G., Rodríguez-Bailón, R., \& Willis, G.B. (2021). Changing attitudes toward redistribution: The role of perceived economic inequality in everyday life and intolerance of inequality. The Journal of Social Psychology. Advance online publication.

https://doi.org/10.1080/00224545.2021.2006126 


\title{
Changing attitudes toward redistribution: The role of perceived economic inequality in everyday life and intolerance of inequality
}

\begin{abstract}
Modern societies are characterized by economic inequality. Redistributive policies are one of the means to reduce it. We argue that perceived economic inequality in everyday life and intolerance of it are central factors to enhance positive attitudes toward redistribution. To test it, we conducted a four-wave longitudinal panel study in Chile with a sample of 1221 college students (at T1 - baseline, 960 at T2, 926 at T3, and 787 at T4; Mage =18.89). As expected, a cross-lagged longitudinal analysis controlled by household income confirmed a positive relationship between perceived economic inequality in everyday life and intolerance of inequality, which in turn was positively associated with support for redistributive policies. These results were stable and consistent over time, supporting the idea that perceived economic inequality in everyday life enhances positive attitudes toward redistribution by increasing intolerance of it. Results highlight the important role played by perceived inequality in everyday life.
\end{abstract}

Keywords: economic inequality, intolerance of inequality, attitudes toward redistribution, everyday life, perceived inequality. 


\section{Changing attitudes toward redistribution: The role of perceived economic inequality in everyday life and intolerance of inequality}

Despite social and economic progress made in the last few centuries, societies still cannot solve a fundamental issue: ongoing economic inequality. This disparity has increased in most societies and is very likely to continue growing in the future (Alvaredo et al., 2017; Piketty, 2014). Chile is one of the countries that leads economic inequality rankings worldwide (Salgado, 2019). Lately, it has received significant international attention because of the civil movement that demands a more equitable society (Somma et al., 2020). In this context, the present research tested the association between Chilean citizens' perceived economic inequality in everyday life and two of its potential effects: intolerance of inequality and attitudes toward redistribution.

Notwithstanding the costs of inequity and the desire to reduce economic inequality (Brown-Ianuzzi et al., 2015; Evans \& Kelly, 2017), people do not often challenge inequality (Hadler, 2005; Kelley \& Evans, 1993). In fact, the redistribution of economic resources is still unpopular among people (Brown-Ianuzzi et al., 2015; Son Hing et al., 2019). Moreover, individuals are not very precise when estimating actual inequality in their countries (Condon \& Wichowsky, 2020; Norton \& Ariely, 2011) and are more inclined to support policies that foster educational opportunities than those aimed at redistributing taxes (McCall \& Kenworty, 2009; Franko, 2016). Furthermore, citizens often do not trust the government to redistribute resources (Arsenio, 2018). Nevertheless, some research has recently suggested that perceived economic inequality in people's daily life - rather than a general and abstract estimation of such inequality - may lead people to tolerate inequality less and be more open to redistribution (García-Castro et al., 2020). 
To measure perceived economic inequality, studies use tasks that ask participants how resources are distributed in their countries, measures such as diagrammatic representations of resource distribution, or perceived wage gaps (Choi, 2019; Norton \& Ariely, 2011). Yet, these measures have raised serious concerns about their construct validity. Participants find it difficult to report their perception of inequality using them. Their answers tend to reflect variability associated with cognitive biases or educational levels (Helgason \& Mérola, 2017; Pedersen \& Mutz, 2019). As a result, numerous studies have pointed out the need to measure economic inequality experienced by people daily rather than use abstract measures of inequality (Boudreau \& Mackenzie, 2018; Cruces et al., 2013; Gonthier, 2017; Mijs, 2019). However, this has rarely been done so far (see Kraus et al., 2017, for exceptions).

Therefore, some qualitative studies have examined how people perceived economic inequality in their daily lives (see García-Sánchez et al., 2018a; García-Castro et al., 2021). They have found that perceived economic inequality is not restricted to financial issues and includes dimensions related to people's routines. For example, individuals identify social classes, intergroup relations founded on discrimination, and job conditions as important indicators of inequality (García-Sánchez et al., 2018). Moreover, people perceived inequality through daily cues such as consumption, opportunities, leisure, and mental health (GarcíaCastro et al., 2021). Finally, some studies remark that the frequency of perceived economic inequality in everyday life influences attitudes toward economic inequality (García-Sánchez et al., 2018; García-Castro et al., 2021).

We aimed to overcome the aforementioned limitation by exploring perceived economic inequality in daily life as a critical factor that may trigger less tolerance of inequality and lead to greater support for redistributive policies over time. This relationship has been theoretically proposed (García-Sánchez et al., 2018b; Son Hing et al., 2019) and preliminarily tested in at least one experimental study (García-Castro et al., 2020). Moreover, 
as far as we know, our research is a novel attempt to examine these ideas using longitudinal data, a recommended approach to test relationships over time, and bring more ecological validity to the results (Elliot et al., 2008; Newman, 2020; Salgado, 2019).

\section{Perceived economic inequality in everyday life, intolerance of inequality, and attitudes toward redistribution}

Perceived economic inequality in daily life is defined as the everyday events during which members of society perceive variability in the distribution of resources amongst themselves (Akyelken, 2020). From this perspective, perceived economic inequality in daily life comprises at least two elements: the places people usually inhabit and the persons who are part of their reference group (García-Sánchez et al., 2018a).

The most critical social circles from which individuals can estimate inequality are those within which people interact the most often in their everyday life (Clark \& Senik, 2010, Irwin, 2015). People gather information about economic distribution based on their own experience and the experiences of their relatives, friends, coworkers, and acquaintances, including only small amounts of information about society as a whole or other abstract images (Evans \& Kelley, 2017; Molina et al., 2019). The information that people extract from their close reference group is applied generally to the entire population (Brown-Ianuzzi et al., 2015; Cruces et al., 2013). In fact, the mechanisms used to extract information about the distribution of society from reference groups are present in many different cultures (Evans \& Kelly, 2017, Kanbayashi, 2019).

Furthermore, the closest context impacts social perception, especially when it is highly salient (Larsen et al., 2019; Newman, 2020). Research on the accessibility heuristic has shown that when people cognitively assess any given situation, they base their judgment on their social circle and close environment (Cruces et al., 2013; Evans \& Kelley, 2017), 
which provides information that influences their assessment of reality (Bisgaard et al., 2016). The most immediate environments exert a remarkable influence on individuals' perception of economic inequality (Evans \& Kelley, 2017; Irwin, 2015; Kanbayashi, 2019).

Attitudes toward redistribution are influenced by perceived economic inequality in daily life (Kearns et al., 2014). Some evidence in this regard has shown that people living in less equal environments are more likely to vote for legislators who espouse policies of wealth redistribution (Newman \& Hayes, 2019). Individuals who interact with people in unemployment situations also tend to support redistribution of wealth to a greater extent compared to those who do not have these types of interactions (Franko, 2016). Moreover, the perceived economic condition of the reference group affects people's attitudes toward wealth redistribution (Dawtry et al., 2015).

Although the previous results show how individuals' context and reference groups can affect their perception of inequality and their tendencies to agree with redistributive measures, attitudes toward inequality can also influence perceived inequality. At a recent time in literature, research has also shown that psychosocial processes can shape perceptions of inequality (Du \& King, 2021; Sainz et al., 2019a). For example, people who have more social dominance orientation (Kteily et al., 2017), believe in a just world (García-Sánchez et al., 2021), and validate a meritocratic ideology (Castillo et al., 2019) perceive less inequality.

Notwithstanding people tend to reject the economic inequality they perceive (e.g., Castillo et al., 2012; Khun, 2019), this is not always the case. The extent to which economic inequality is tolerated is a function of people's perception and beliefs about it (LA Roex et al., 2019; Han et al., 2012). Indeed, perceived economic inequality in daily life has been shown to predict better intolerance of inequality than the existing popular measures of a general perception of inequality (García-Castro et al., 2019). In addition, it has also been 
found experimentally that perceived economic inequity in everyday life increases intolerance of inequality (García-Castro et al., 2020). Therefore, perceived economic disparity in daily life seems to be a more reliable predictor than an abstract measure of perceived inequality.

The effect of perceived economic inequality in support for redistributive policies appears not to be direct (Choi, 2019; Norton \& Ariely, 2011) but mediated by intolerance of inequality (García-Castro et al., 2020). Perceiving greater inequality in everyday life may make people tolerate inequality less; in turn, this may lead people to support redistributive policies (García-Castro et al., 2020). Empirical evidence has previously confirmed this idea and revealed that intolerance of inequality is related to support redistributive policies. When intolerance of inequality is high, people show more support for redistributive policies (Franko et al., 2013; Kuziemko et al., 2015).

People tend to congregate and interact within social groups composed of individuals similar to themselves regarding their socioeconomic status (Cruces et al., 2013). When social groups are homophilic economic inequality is not visible (Son \& Lin, 2012). Then, the social distance between social groups results in a lack of consciousness about the structural reasons that create inequality (Mijs, 2019). Conversely, when people become aware of the inequality around them in their daily lives, their tolerance for inequality decreases, and they support more redistributive policies (García-Castro et al., 2020). As socioeconomic status can influence this process (Akyelken, 2020; Irwin, 2015), we control this variable when testing PEIEL's effect.

\section{The current research}

Our contribution is based on two aspects. First, to test the hypothesized model, we used a longitudinal panel methodology with four waves of data collection. As far as we know, this design has not been used before to test this model. This design provided optimal 
conditions to test how perceived economic inequality in everyday life influences changes in support for redistributive policies over time directly and indirectly by reducing the level of tolerance to inequality (see Figure 1). We would also replicate a previous result to provide greater ecological validity to the model (Baucal et al., 2020). Second, the study presented here was conducted in a sample of the non-Western, Educated, Industrialized, Rich and Democratic (WEIRD) population (Rad et al., 2018) in Latin America. This region has not often been represented in the literature on economic inequality and support for redistributive policies.

Specifically, we hypothesize that the more people perceive economic inequality in their daily life, the higher their support for redistributive policies (H1) and the higher their intolerance of inequality over time $(\mathrm{H} 2)$. We also expect the association between perceived economic inequality in everyday life and support for redistributive policies to be mediated by the level of intolerance of inequality over time (H3). Thus, we consider that perceived economic inequality would predict support for redistributive policies controlled by household income because it increases the level of intolerance of inequality over time. Figure 1 shows the tested model. Likewise, we explore the possibility that intolerance to inequality and attitudes toward redistribution affects the perception of economic inequality in everyday life. Supplementary materials, data, and analyses' scripts are available at https://osf.io/yjexs/?view_only=c4d80f18dd464e0e93b60a5c6d17899a

\section{[FIGURE 1 HERE]}

\section{Method}

\section{Participants}

First-year university students from five different schools in Santiago, Chile, were enrolled in the first part of a longitudinal panel study $\left(N=1221 ; M_{\text {age }}=18.89, S D_{\text {age }}=1.6,66 \%\right.$ women), 960 (67\% women) at T2, 926 at T3 (67\% women), and 787 at T4 (68.6\% women). 
Attrition rates were generally low, meaning that only $21.42 \%$ of participants dropped out at $\mathrm{T} 2,1.15 \%$ at $\mathrm{T} 3$, and $4.03 \%$ at $\mathrm{T} 4$.

\section{Procedure}

Participants were recruited using social media networks as well as on campus. Research assistants recruited them using a message describing the study, the reward for participation, and its longitudinal design. Individuals interested in participating in the study were instructed to share their contact information to be sent the Qualtrics survey link. After giving their informed consent and receiving guarantees regarding data confidentiality and anonymity, participants answered a questionnaire comprising the target measures that took about 45 minutes to complete. The time lag between waves was 6 months (Wave 1 took place in May 2017, Wave 2 was in November 2017, Wave 3 was in May 2018, and Wave 4 was in November 2018); data collection took about one month. After completing the questionnaire, participants were thanked and rewarded with $\$ 10, \$ 12, \$ 15$, and \$20 USD, respectively, in each wave.

The study data was collected in the context of a broader project addressing social change and collective action. The project had the approval of the Ethics Committee. The sample size was initially set to enable a series of analyses despite attrition rates. Hence, the sample size for this study was determined by its availability considering the number of participants needed to perform structural equation models ( $N>460)$ (Wolf et al., 2013) and a mediation analysis (N>562) (Fritz \& MacKinnon, 2007) with a statistical power of at least 80\%. All available data for each participant were used. Full Information Maximum Likelihood (FIML) procedure was applied to impute missing data. Accordingly, missing data can partly be recuperated from previous waves, making this statistical procedure a powerful tool for dealing with missing data (Schafer \& Graham, 2002; Wothke, 2000). 


\section{Measures}

All measures remained constant for the entire study.

Perceived Economic Inequality in Everyday Life (PEIEL). Adapted from (GarcíaCastro et al., 2019), a single item measures this variable. We asked participants to report the frequency of perceived economic inequality in their everyday life by answering the following question (from 1 = never, to 5 = very frequently): "How often do you see situations of economic inequality in your daily life?" PEIEL's measures in recent studies have shown satisfactory validity evidences (see Melita et al., 2021; Sánchez-Rodríguez et al., 2020).

Intolerance of inequality. This study considered a single item commonly used in international surveys (e.g., ISSP, 2017). Participants were questioned about their level of agreement or disagreement $(1=$ totally agree, $5=$ totally disagree $)$ with the following question: "In Chile, income differences are too large." This measure was conceptualized as tolerance of inequality (Gonthier, 2017; Larsen, 2016; Schröder, 2017). Considering higher scores of this measure have been shown to mean lower tolerance for inequality, we designate said measure as intolerance of inequality.

Attitudes toward redistribution. Two items adapted from Dawtry et al. (2015) were used to measure support for redistributive policies. Participants were questioned about their level of agreement or disagreement $(1=$ totally agree, $5=$ totally disagree $)$ with the following statements: "I think the government should redistribute wealth charging higher taxes to rich people." and "Wealth in this country should be distributed more equitably, also reaching groups with fewer resources." The results from these two items were then averaged to produce one score at each given time ( $r$ ranging from .53 to .61 ).

Household Income. Monthly family income in Chilean pesos after taxes and deductions were asked with 20 options $1=$ below $\$ 220.000,2=$ between $\$ 220.001$ and $\$ 280.000$, 
3=between $\$ 280.001$ and $\$ 330.000,4=$ between $\$ 330.001$ and $\$ 380.000,5=$ between $\$ 380.001$ and $\$ 420.000,6=$ between $\$ 420.001$ and $\$ 470.000,7=$ between $\$ 470.001$ and $\$ 510.000$, $8=$ between $\$ 510.001$ and $\$ 560.000,9=$ between $\$ 560.001$ and $\$ 610.000,10=$ between $\$ 610.001$ and $\$ 670.000,11=$ between $\$ 670.001$ and $\$ 730.000,12=$ between $\$ 730.001$ and $\$ 800.000$, $13=$ between $\$ 800.001$ and $\$ 890.000,14=$ between $\$ 890.001$ and $\$ 980.000,15=$ between $\$ 980.001$ and $\$ 1.100 .000,16=$ between $\$ 126.001$ and $\$ 149.000,17=$ between $\$ 1.260 .001$ and $\$ 1.490 .000,18=$ between $\$ 1.490 .001$ and $\$ 1.850 .000,19=$ between $\$ 1.850 .001$ and $\$ 2.700 .000$, $20=$ above $\$ 2.700 .000$. The average response ranged between $\$ 670.001$ and $\$ 730.000$ which is approximately between $\$ 971$ and \$1011 US dollars.

\section{Results}

\section{Descriptive statistics}

Correlations of the same measures over time, standard deviations, and means at their corresponding time points are displayed below in Table 1. As expected, the correlations between the same variables over time reported in Table 1 were significantly positive, ranging in size from .36 to .84 .

\section{[TABLE 1 HERE]}

Table 2 shows the variable's correlations matrix measured at the same time point. The cross-wide relationships between variables are from low to moderate (Swank \& Mullen, 2017).

\section{[TABLE 2 HERE]}

\section{Structural model}

To estimate the longitudinal effect of PEIEL on attitudes toward redistribution and the mediating role of intolerance of inequality at four data time points, we conducted longitudinal 
cross-lagged path analyses with the robust maximum likelihood estimation in Mplus version 8.2 (Muthén \& Mutheén, 2018). Our baseline model included only autoregressive effects between variables estimated over time. The model was then systematically compared with others that constrained the autoregressive effects for each variable to be equal across different time points. If the later models did not substantially change the control format indicator (CFI) and Root Mean Square Error of Approximation (RMSEA) indicators, we retained and interpreted the most parsimonious constrained model results in which the stability of variable scores across different time points was the same. This decision was made using the criteria introduced by Rutkowski and Svetina (2014) and suggestions by Chen (2007). When determining invariance between different models with samples bigger than 300 participants, these authors recommend focusing on the change in the CFI and RMSEA of the models as follows: the decrease in the CFI should not be greater than .02 when compared to the previous model, and the RMSEA should not change by more than .03 . It is worth noting that Chen (2007) and Rutkowski and Svetina (2014) argued that the traditional scaled chi-square difference test (Satorra \& Bentler, 2001) is less recommended when comparing models with large samples because it is a sensitive technique that shows significant changes even if the variations in the fit of the models are minimal. Unstandardized parameters are reported because standardized parameters can result in inaccurate estimates and standard errors (Cole \& Maxwell, 2003). Results are summarized in Table 3.

\section{[TABLE 3 HERE]}

\section{Autoregressive longitudinal model}

It is important in the longitudinal analysis to evaluate if the variables are predictors of themselves over time (Usami et al., 2019). Therefore, the first analysis tested a first-order autoregressive model. The parameters in the first model (1a) were freely estimated. After this 
model was tested, a second model (see Table 3, Model 1b) assessed if the autoregressive effects between $\mathrm{T} 1$ and $\mathrm{T} 2$ were equivalent to those between $\mathrm{T} 2$ and $\mathrm{T} 3$ and between $\mathrm{T} 3$ and T4; specifically, it assessed whether the stability in a variable was itself consistent over time (Cole \& Maxwell, 2003). Since invariance between models was confirmed $(\Delta \mathrm{CFI}=.001$; $\triangle \mathrm{RMSEA}=-.004)$, the second, most parsimonious model (Model 1b) was retained. All estimated paths were significant $(\mathrm{p}<.001)$ in this model, which indicates that the variables predicted themselves, showing the stability of the constructs over time.

\section{Unidirectional forward longitudinal models}

The next model was built on the autoregressive model (Model 1b) by estimating the hypothesized paths between the predictor (i.e., perceived economic inequality in everyday life T1 and T2), the mediator (i.e., intolerance of inequality T2 and T3), and the outcome variable (i.e., attitudes toward redistribution T3 and T4), respectively. Again, the model showed a good fit (see Table 3, Model 2a). The next step was to constrain the hypothesized pathways to be equivalent between $\mathrm{T} 1$ and $\mathrm{T} 2$, between $\mathrm{T} 2$ and $\mathrm{T} 3$, and between $\mathrm{T} 3$ and $\mathrm{T} 4$. This more constrained model also showed a good fit (see Table 3, Model 2b) and did not significantly differ from the former $(\Delta \mathrm{CFI}=-.015 ; \Delta \mathrm{RMSEA}=.000)$. Hence, the more restrained Model 2b was retained (see Figure 2).

\section{[FIGURE 2 HERE]}

Results revealed that perceived economic inequality in daily life predicted a change in respondents' attitudes toward redistribution to reduce inequality. Consistent with $\mathrm{H} 1$, the greater the perceived level of economic inequity in everyday life at Time 1, Time 2, and Time 3, the more participants increased their attitudes toward redistribution over the subsequent time points (i.e., six months T2, one-year T3, and eighteen months later T4). In addition, and 
consistent with $\mathrm{H} 2$, perceived economic inequality in daily life predicted an increase in the level of intolerance of inequality six months later, which in turn predicted a rase in participants' positive attitudes toward redistribution to reduce inequality six months later (see the significant indirect effect in Table 4). Thus, this pattern of results strongly supported H3 and provided evidence of the longitudinal mediating role of intolerance of inequality in the relationship between perceived economic disparity in daily life and attitudes toward redistribution.

\section{[TABLE 4 HERE]}

\section{Unidirectional reverse longitudinal models}

To test the reverse relationship, the predictor and outcome variables were then swapped. In this model, T1 and T2 attitudes towards redistribution were considered predictors of T2 and T3 intolerance of inequality, which were predictors of T3 and T4 perceived economic inequality in everyday life. This reverse model also showed a good fit, as is shown in Table 3 (Model 3a). Similar pathways were constrained to be equivalent in magnitude between time points as in the unidirectional forward model. This inverse model with equivalent paths exhibited good fit indices (see Model 3b) and demonstrated no significant decrease in fit compared to an unconstrained Model 3a $(\triangle \mathrm{CFI}=-.011 ; \Delta \mathrm{RMSEA}=$ $-.002)$.

The reverse indirect path from attitudes towards redistribution at Time 1 and Time 2 to perceived economic inequality in everyday life at Time 3 and Time 4 via intolerance of inequality at Time 2 and T3 was significant (See Table 4), indicating the presence of a mediation. Models $3 \mathrm{~b}$ and $2 \mathrm{~b}$ had similar fit indices ( see Table $3 ; \Delta \mathrm{CFI}=.006 ; \Delta \mathrm{RMSEA}=-$ $.003)$, suggesting that neither model was preferable over the other. We then tested a 
bidirectional longitudinal model that simultaneously estimated both the 'forward' and 'reverse' paths. It is reported in the next section.

\section{Bidirectional longitudinal models}

Given that perceived economic inequality in daily life predicted an increase in positive attitudes toward redistribution, and attitudes toward redistribution predicted a rise in perceived economic inequality in everyday life, we combined the pathways from the unidirectional longitudinal (forward and reverse) models. Including the bidirectional longitudinal models allowed us to test whether the variables had a recursive effect in an exploratory way. The first bidirectional model was freely estimated, except for the autoregressive pathways that were already constrained to be equivalent in magnitude between $\mathrm{T} 1$ and $\mathrm{T} 2, \mathrm{~T} 2$ and $\mathrm{T} 3$, and $\mathrm{T} 3$ and T4, as in previous models. The bidirectional model fit well statistically (see Table 3, Model 4a) and was then compared with a model in which equivalent pathways were constrained to be equal in magnitude between different time points (Table 3 , Model $4 b)$. The two models did not vary in terms of fit $(\Delta \mathrm{CFI}=-.014 ; \Delta \mathrm{RMSEA}=-.003)$, so the most parsimonious bidirectional model was treated as the definitive parameter estimation (Model 4b, see Figure 3). These results suggest that a recursive relationship between variables is possible. Thus, a reciprocal influence between perceived economic inequality in daily life and attitudes toward redistribution over time was observed in this final model mediated by intolerance of inequality.

[FIGURE 3 HERE]

\section{Discussion}

One of the most pressing issues in contemporary society is economic inequity (Wilkinson \& Pickett, 2017), and economic redistribution seems to be a valuable way to reduce it (García-Sánchez et al., 2020; Sainz et al., 2019b). This research explored one of the 
possible antecedents of attitudes toward inequality and redistribution: perceived economic inequality in daily life. Consistent with our predictions, results revealed that the extent to which people perceive economic inequality in everyday life relates to attitudes toward redistributive policies over time (H1). In addition, as expected, perceived economic inequality in daily life also predicted changes in the level of intolerance of inequality, making people less tolerant toward it (H2). Finally, results confirmed the central role played by intolerance of inequality in the process of linking economic inequality in daily life and attitudes toward redistribution (H3). Specifically, the more individuals were exposed to economic inequality in their everyday lives, the higher their intolerance. Increasing intolerance of inequality, in turn, fostered the development or growth of positive attitudes toward redistribution over time. The outcomes are given even controlling for household income. The current results are relevant for many reasons.

First, the class structure of society leads individuals to perceive and estimate inequality based on the social groups they interact with (Cruces et al., 2013; Mijs, 2019). These processes may distance individuals from different social groups - more or less disadvantaged than themselves - which, in turn, could make people unaware of the structural reasons that cause inequality. It has been shown that attitudes toward inequality tend not to change without direct experiences with people from different social strata (Condon \& Wichowsky, 2020). Furthermore, the contact theory (Allport, 1954; Pettigrew \& Tropp, 2006) could explain the effect of perceived economic inequality in everyday life on attitudes towards inequality and redistribution. Perceived economic inequality in daily life leads individuals to make comparisons between advantaged and disadvantaged close others, which leads them to question these disparities. In line with this idea, past research has shown that individuals who make more economic comparisons between people show greater support for wealth redistribution policies (Clark \& Senik, 2010; Senik, 2009). 
Second, having experiences that increase knowledge about inequality can change attitudes toward it over time (Kearns et al., 2014). Previous research has shown that inequality poses a threat to the self-concept (Lowery et al., 2012; Rosette \& Zhou, 2018). Therefore, increases in perceived economic inequality in daily life could threaten the social standing of individuals, given that those who often perceive economic disparities in their everyday lives may be more afraid of losing social status (García-Castro et al., 2019). This can lead to decreased tolerance of wealth disparity and more support of redistribution (García-Sánchez et al., 2018a).

To our knowledge, this the first study that has shown how perceived economic inequality in daily life relates to support redistributive policies over time. Beliefs linked to inequalities tend to reinforce themselves, making them hard to change (Brown-Ianuzi et al., 2015). However, attitudes are conditioned by knowledge gathered from everyday life (Kearns et al., 2014). The current results show that changes in attitudes seem to require time. Everyday knowledge about inequality is accumulated thanks to the information gathered from social groups, interpersonal contact, and direct observations, providing information on redistributive policies (Kearns et al., 2014). Longitudinal studies appear to be an adequate tool to track how this accumulation of daily knowledge affects support for redistributive policies (Newman, 2020).

The relationship between wealth disparity and support for redistributive policies is complex and not necessarily straightforward (Evans \& Kelley, 2018). The aforementioned results of this study provide substantive evidence to support the mediational process involved in the relationship between perceived economic inequality in daily life and attitudes toward redistribution through intolerance of inequality. 
Despite these promising findings, we are conscious of the limits of mediation models (Fiedler et al., 2018) and the partial mediation showed in the current study. Nevertheless, we argue that intolerance of inequality could be understood as one of several mechanisms at play in the relationship between perceived economic disparities in daily life and attitudes toward redistribution. Future research could test other possible mediators involved in this relationship, such as justice or meritocracy beliefs.

Although in some cases, single-item measures are as valid and reliable as broader instruments (Du \& King, 2021; Postmes et al., 2013), we acknowledge that the items used to measure perceived economic inequality in daily life and intolerance of inequality could be improved. For example, in the case of perceived economic inequality in everyday life, more items of PEIEL's scale may be used (García-Castro et al., 2019). Unfortunately, the space limit in the questionnaire used constrained the possibility of including more items, which frequently happens in extensive surveys.

Notwithstanding perceived economic inequality and intolerance of inequality refer to subjective elements of economic disparities and, they evaluate different cognitive processes (Son Hing et al., 2019). The measured "Income differences [in country] are too large" is an attitudinal measure of the level of rejection or acceptance generated by perceived inequality (Choi, 2019). The adjective "too large" involves assessing whether there is more inequality than there should be. For this reason, this measure is conceptualized as intolerance to inequality (see García-Castro et al., 2019, 2020, 2021; Gonthier, 2017; Larsen, 2016; Schröder, 2017). Besides, it is the most used measure in international surveys (ISSP, 2017). However, since intolerance to inequality is a crucial variable in social psychology, new multiitem measures of this construct should also be considered in future studies (see Wiwad et al., 2019). 
The present results also show important evidence supporting a bidirectional and dynamic relationship among the variables, influencing each other with a recursive effect. Perceived economic inequality in daily life leads to intolerance of inequity and support for wealth redistribution; yet, the support of redistributive policies also causes intolerance of inequality and a greater perception of economic inequality in daily life. This lines up with previous research suggesting the possible bidirectional relationship mentioned above (Bobzien, 2019; Castillo et al., 2019). The evidence provided in the present research offers insight into this recursive dynamic approach.

The main focus of this study was the psychosocial consequences of perceived economic inequality in daily life. However, results must be taken with caution to the extent that they seem to point out that unidirectional linear models account for only a small part of the psychosocial processes involved and because the measures used play an important role in understanding the results found. This is inferred by considering the small effect size found in this study and in the previous one that experimentally tested the same mediation path (GarcíaCastro et al., 2020).

The present study results support recent findings showing that attitudes toward inequality can also predict perceived economic inequality over time (Du \& King, 2021). This result has been explained by a motivated cognition process (Aldama et al., 2021). Those who tolerate and justify more inequality perceive less inequality just because they are motivated to not seeing it. In this way, conservatives defend themselves from the damaging effects of perceiving economic inequality (Du \& King, 2021). Furthermore, having positive attitudes toward redistribution and tolerate less inequality can lead to perceiving more inequality. All in all, this process helps to maintain a more consistent view of society, and cognitive dissonance is reduced (Aldama et al., 2021). Future research should explore this dynamic 
relationship in greater depth to deepen our understanding of the processes that are at play in this rather complex phenomenon.

In conclusion, the results of this study confirmed that directing people's focus to the wealth disparity in their daily lives relates to their concern about inequality and their support to policies to reduce it. Likewise, it shows the benefits of longitudinal studies to capture the psychosocial changes over time of perceived economic inequality in everyday life. If we want to build more egalitarian societies, developing interventions that highlight the perception and experience of inequality in daily life can be a way to promote more positive attitudes toward actions aimed to reduce inequality.

\section{Declaration of conflicting interests}

The authors declare that there is no conflict of interest.

\section{Data statement}

The article's data is publicly available on the following site:

https://osf.io/yjexs/?view_only=c4d80f18dd464e0e93b60a5c6d17899a

\section{References}

Akyelken, N. (2020). Urban conceptions of economic inequalities. Regional Studies, 54(6), 863-872. https://doi.org/10.1080/00343404.2020.1732902

Aldama, A., Bicchieri, C., Freundt, J., Mellers, B., \& Peters, E. (2021). How perceptions of autonomy relate to beliefs about inequality and fairness. Plos One, 16(1): e0244387. https://doi.org/10.1371/journal.pone.0244387

Allport, G.W. (1954). The nature of prejudice. Cambridge, MA: Perseus Books. 
Alvaredo, F., Chancel, L., Piketty, T., Saez, \& E., Zucman. (Eds.). (2017). World inequality report 2018. World Inequality Lab. Retrieved February 18, 2019: https://wir2018.wid.world/

Arsenio, W. (2018). The wealth of nations: International judgments regarding actual and ideal resource distributions. Current Directions in Psychological Science, 27(5), 357362. https://doi.org/10.1177/0963721418762377

Baucal, A., Gillespie, A., Krstic, K., \& Zittuon, T. (2020). Reproducibility in Psychology: Theoretical distinction of different types of replications. Integrative Psychological and Behavioral Science, 54, 152-157. https://doi.org/10.1007/s12124-019-09499-y

Bisgaard, M., Thisted, P., \& Mannemar, K. (2016). Reconsidering the neighborhood effect: does exposure to residential unemployment influence voters' perceptions of the national economy? The Journal of Politics, 78(3), 719-732. https://doi.org/10.1086/685088

Bobzien, L. (2019). Polarized perceptions, polarized preferences? Understanding the relationship between inequality and preferences for redistribution. Journal of European Social Policy, 1-19. https://doi.org/10.1177/0958928719879282

Boudreau, C., \& MacKenzie, S. (2018). Wanting what is fair: how party cues and information about income inequality affect public support for taxes. The Journal of Politics, 80(2), 367-381. https://doi.org/10.1086/694784

Brown-Iannuzzi, J., Lundberg, K., Kay, A., \& Payne, K. (2015). Subjective status shapes political preferences. Psychological Science, 26(1), 15-26. https://doi.org/10.1177/0956797614553947 
Castillo, J.C., Miranda, D., \& Carrasco, D. (2012). Percepción de desigualdad económica en Chile: Medición, diferencias y determinantes. Psyke, 21(1), 99-114. https://doi.org/10.7764/psykhe.21.1.501

Castillo, J.C., Torres, A., Atria, J., \& Maldonado, L. (2019). Meritocracia y desigualdad económica. Percepciones, preferencias e implicancias. Revista Internacional de Sociología, 77(1), 1-15. https://doi.org/10.3989/ris.2019.77.1.17.114

Chen, F. (2007). Sensitivity of goodness of fit indexes to lack of measurement invariance. Structural Equation Modeling, 14(3), 464-504. https://doi.org/10.1080/10705510701301834

Choi, G. (2019). Revisiting the redistribution hypothesis with perceived inequality and redistributive preferences. European Journal of Political Economy, 58, 220-244. https://doi.org/10.1016/j.ejpoleco.2018.12

Clark, A., \& Senik, C. (2010). Who compares to whom? The anatomy of income comparison in Europe. The Economic Journal, 120(544), 573-594. https://doi.org/10.1111/j.14680297.2010.02359.x

Cole, D. A., \& Maxwell, S. E. (2003). Testing mediational models with longitudinal data: Questions and tips in the use of structural equation modeling. Journal of Abnormal Psychology, 112, 558-577. https://doi.org/10.1037/0021-843X.112.4.558

Condon, M., \& Wichowsky, A. (2020). Inequality in the social mind: social comparison and support for redistribution. The Journal of Politics, 82(1), 149-161. https://doi.org/10.1086/705686 
Cruces, G., Perez-Truglia, R., \& Tetaz, M. (2013). Biased perceptions of income distribution and preferences for redistribution: evidence from a survey experiment. Journal of Public Economics, 98, 100-112. https://doi.org/10.1016/j.jpubeco.2012.10.009

Dawtry, R., Sutton, R., \& Sibley, C. (2015). Why wealthier people think people are wealthier, and why it matters: from social sampling to attitudes to redistribution. Psychological Science, 26(9), 1389-1400. https://doi.org/10.1177/0956797615586560

Du, H., \& King, R. (2021). What predicts perceived economic inequality? The roles of actual inequality, system justification, and fairness considerations. British Journal of Social Psychology, https://doi.org/10.1111/bjso.12468

Elliot, J., Holland, J., \& Thompson, R. (2008). Longitudinal and panel studies. In Alasuutaria, P., Bickman, L., \& Brannen, J. The SAGE handbook of social research methods (pp.228-248). London: SAGE Publications Ltd. https://doi.org/10.4135/9781446212165

Evans, M., \& Kelley, J. (2017). Communism, capitalism, and images of class: Effects of reference groups, reality, and regime in 43 nations and 110,000 individuals, 19872009. Cross-Cultural Research, 51(4), 315-359.

https://doi.org/10.1177/1069397116677963

Evans, M., \& Kelley, J. (2018). Strong welfare states do not intensify public support for income redistribution, but even reduce it among the prosperous: A multilevel analysis of public opinion in 30 countries. Societies, 8(15), 1-52. https://doi.org/10.3390/soc8040105

Fiedler, K., Harris, C., \& Schott, M. (2018). Unwarranted inferences from statistical mediation tests - An analysis of articles published in 2015. Journal of Experimental Social Psychology, 75, 95-102. https://doi.org/10.1016/j.jesp.2017.11.008 
Franko, W. (2016). Political context, government redistribution, and the public's response to growing economic inequality. The Journal of Politics, 78(4), 957-973. https://doi.org/10.1086/686025

Franko, W., Tolbert, C., \& Witko, C. (2013). Inequality, self-interest, and public support for “Robin Hood" tax policies. Political Research Quarterly, 66(4), 923-937. https://doi.org/10.1177/1065912913485441

Fritz, M., \& MacKinnon, D. (2007). Required sample size to detect the mediated effect. Psychological Science, 18(3), 233-239. https://doi.org/10.1111/j.14679280.2007.01882.x

García-Castro, J.D., García-Sánchez, E., Montoya-Lozano, M., \& Rodríguez-Bailón, R. (2021). The perception of economic inequality in everyday life: My friends with the most and least money. Asian Journal of Social Psychology. Advance online publication. https://doi.org/10.1111/ajsp.12476

García-Castro, JD., Rodríguez-Bailón, R., \& Willis, G. (2020). Perceiving economic inequality in everyday life decreases tolerance to inequality. Journal of Experimental Social Psychology, 90, https://doi.org/10.1016/j.jesp.2020.104019

García-Castro, J.D., Willis, G.B., \& Rodríguez-Bailón, R. (2019). I know people who can and who cannot: A measure of the perception of economic inequality in everyday life. The Social Sciences Journal, 56(4), 599-608. https://doi.org/10.1016/j.soscij.2018.09.008

García-Sánchez, E., Correia, I., Cícero, R., Willis, G., Rodríguez-Bailón, R., \& Vala, J. (2021). How fair is economic inequality? Belief in a just world and the legitimation of economic disparities in 27 European Countries. Personality and Social Psychological Bulletin, https://doi.org/10.1177/01461672211002366 
García-Sánchez, E., Osborne, D., Willis, G.B., \& Rodríguez-Bailón, R. (2020). Attitudes towards redistribution and the interplay between perceptions and beliefs about inequality. British Journal of Social Psychology, 59(1), 111-136. https://doi.org/10.1111/bjso.12326

García-Sánchez, E., Willis, G.B., Rodríguez-Bailón, R., García-Castro, J.D., Palacio-Sañudo, J., Polo, J., \& Rentería-Pérez, E. (2018a). Perceptions of economic inequality in colombian daily life: More than unequal distribution of economic resources. Frontiers in Psychology, 9:1660. https://doi.org/10.3389/fpsyg.2018.016609

García-Sánchez, E., Willis, G.B., Rodríguez-Bailón, R., Palacio, J., Polo, J., \& Rentería, E. (2018b). Perceptions of economic inequality and support for redistribution: the role of existential and utopian standards. Social Justice Research, 31, 335-354. https://doi.org/10.1007/s11211-018-0317-6

Gonthier, F. (2017). Baby boomers still in the driver's seat? How generational renewal shapes the dynamics of tolerance for income inequality. International Journal of Sociology, 47(1), 26-42. https://doi.org/10.1080/00207659.2017.1264833

Hadler, M. (2005). Why do people accept different income ratios? A multi-level comparison of thirty countries. Acta Sociologica, 48 (2), 131-154. https://doi.org/10.1177/0001699305053768

Han, C., Janmaat, G., Hoskins., \& Green, A. (2012). Perceptions of inequalities: implications for social cohesion, published by the Centre for Learning and Life Chances in Knowledge Economies and Societies at: http://www.llakes.org

Helgason, A., \& Mérola, V. (2017). Employment insecurity, incumbent partisanship, and voting behavior in comparative perspective. Comparative Political Studies, 50 (11), 1489-1523. https://doi.org/10.1177/0010414016679176 
Hu, L., \& Bentler, P. M. (1999). Cutoff criteria for fit indexes in covariance structure analysis: Conventional criteria versus new alternatives. Structural Equation Modeling, 6, 1-55. https://doi.org/10.1080/10705519909540118

Irwin, S. (2015). Class and comparison: subjective social location and lay experiences of constraint and mobility. The British Journal of Sociology, 66(2), 259-281. https://doi.org/10.1111/1468-4446.12121

ISSP Research Group. (2017). International Social Survey Programme: Social Inequality IV ISSP 2009. GESIS Data Archive, Cologne. ZA5400 Data file Version 4.0.0, https://doi.org/10.4232/1.12777

Kanbayashi, H. (2019). The changing images of Japan's social stratification: the other side of the quiet transformation. Social Science Japan Journal, 22(1), 45-63. https://doi.org/10.1093/ssjj/jyy048

Kearns, A., Bailey, N., Gannon, M., Livingston., \& Leyland, A. (2014). All in it together? Social cohesion in a divided society: attitudes to income inequality and redistribution in a residential context. Journal of Social Policy, 43(3), 453-477. https://doi.org/10.1017/S0047279414000063

Kelley, J., \& Evans, D. (1993). The legitimation of inequality: occupational earnings in nine nations. American Journal of Sociology, 99(1), 75-125. https://doi.org/10.1086/230230

Kraus, M., Park, J., \& Tan, J. (2017). Experience of economic inequality in everyday life.

Perspectives on Psychological Science, 12(3), 422-435. https://doi.org/10.1177/1745691616673192

Kteily, N. S., Sheehy-Skeffington, J., \& Ho, A. K. (2017). Hierarchy in the eye of the beholder: (Anti-) egalitarianism shapes perceived levels of social inequality. Journal of 
Personality and Social Psychology, 112(1), 136-159. https://doi.org/10.1037/pspp0000097

Kuhn, A. (2019). The subversive nature of inequality: Subjective inequality perceptions and attitudes to social inequality. European Journal of Political Economy, 59, 331-344. https://doi.org/10.1016/j.ejpoleco.2019.04.004

Kuziemko, I., Norton, M. I., Saez, E., \& Stantcheva, S. (2015). How elastic are preferences for redistribution? Evidence from randomized survey experiments. American Economic Review, 105, 1478-1508. https://doi.org/ 10.1257/aer.20130360

LA Roex, K., Huijts, T., \& Sieben, I. (2019). Attitudes towards income inequality: 'winners' versus 'losers' of the perceived meritocracy. Acta Sociologica, 62(1), 47-63. https://doi.org/10.1177/0001699317748340

Larsen, C. (2016). How three narratives of modernity justify economic inequality. Acta Sociologica, 59(2), 93-111. https://doi.org/10.1177/0001699315622801

Larsen, M., Hjorth, F., Dinesen, P., \& Sonderskov, K. (2019). When do citizens respond politically to the local economy? Evidence from registry data on local housing markets. American Political Science Review, 113(2), 499-516. https://doi.org/10.1017/S0003055419000029

Lowery, B. S., Chow, R. M., Knowles, E. D., \& Unzueta, M. M. (2012). Paying for positive group esteem: How inequity frames affect whites' responses to redistributive policies. Journal of Personality and Social Psychology, 102, 323-336. https://doi.org/10.1037/a0024598 
McCall, L., \& Kenworthy, L. (2009). American's social policy preferences in the era of rising inequality. Perspectives on Politics, 7(3), 459-484. https://doi.org/10.1017/S1537592709990818

Melita, D., Willis, G., \& Rodríguez-Bailón, R. (2021). Economic inequality increases status anxiety through perceived contextual competitiveness. Frontiers in Psychology, 12:637365, https://doi.org/10.3389/fpsyg.2021.637365

Mijs, J. (2019). The paradox of inequality: Income inequality and belief in meritocracy go hand in hand. Socio-Economic Review, https://doi.org/10.1093/ser/mwy051

Molina, M., Bucca, M., \& Macy, M. (2019). It's not just how the game is played, it's whether you win or lose. Science Advances, 5(7), 1-7. https://doi.org/10.1126/sciadv.aau1156

Muthén, L.K., \& Muthén, B.O. (2018). Mplus User's Guide. Eighth Edition. Los Ángeles, CA: Muthén \& Muthén.

Newman, B., \& Hayes, T. (2019). Durable democracy? Economic inequality and democratic accountability in the new gilded age. Political Behavior, 41(1), 5-30. https://doi.org/10.1007/s11109-017-9435-3

Newman, B. (2020). Inequality growth and economic policy liberalism: an updated text of a classic theory. The Journal of Politics, 82(2), 765-770. https://doi.org/10.1086/706598

Norton, M., \& Ariely, D. (2011). Building a better America-one wealth quintile at a time. Perspectives on Psychological Science, 6(1), 9-12. https://doi.org/10.1177/1745691610393524

Pedersen, R., \& Mutz, D. (2019). Attitudes toward economic inequality: The illusory agreement. Political Science Research and Methods,7(4), 835-851. https://doi.org/10.1017/psrm.2018.18 
Pettigrew, T., \& Tropp, L. (2006). A meta-analytic test of intergroup contact theory. Journal of Personality and Social Psychology, 90(5), 751-783. https://doi.org/10.1037/00223514.90.5.751

Piketty, T. (2014). Capital in the Twenty-First Century. Cambridge, MA: Belknap Press.

Postmes, T., Haslam, S.A., \& Jans, L. (2013). A single-item measure of social identification: Realibility, validity, and utility. British Journal of Social Psychology, 52, 597-617. https://doi.org/10.1111/bjso.12006

Rad, M.S., Martingano, A.J., \& Ginges, J. (2018). Toward a psychology of homo sapiens: making psychological science more representative of the human population. PNAS, 115(45), 11401-11405. https://doi.org/10.1073/pnas.1721165115

Rosette, A., \& Zhou, C. (2018). Framing advantageous inequity with a focus on others: a catalyst for equity restoration. Journal of Experimental Social Psychology, 76, 283 289. https://doi.org/10.1016/j.jesp.2018.03.002

Rutkowski, L., \& Svetina, D. (2014). Assessing the hypothesis of measurement invariance in the context of large-scale international surveys. Educational and Psychological Measurement, 74(1), 31-57. https://doi.org/10.1177/0013164413498257

Sainz, M., Martínez, R., Rodríguez-Bailón, R., \& Moya, M. (2019a). Where does the money come from? Humanizing high socioeconomic status groups undermines attitudes toward redistribution. Frontiers in Psychology, 10:771, https://doi.org/10.3389/fpsyg.2019.00771

Sainz, M., Martínez, R., Sutton, R., Rodríguez-Bailón, R., \& Moya, M. (2019b). Less human, more to blame: Animalizing por people increases blame and decreases support for 
wealth redistribution. Group Processes \& Intergroup Relations, 23(4), 546-559. https://doi.org/10.1177\%2F1368430219841135

Salgado, M. (2019). Adolescent's justice evaluations of earning gaps in an unequal country: evidence from Chile. Young, 28(3), 294-314. https://doi.org/10.1177/1103308819886467

Sánchez-Rodríguez, A., Rodríguez-Bailón, R., Willis, G. (2020). Economic inequality affects perceived normative values. Group Processes \& Intergroup Relations, https://doi.org/10.1177\%2F1368430220968141

Satorra, A., \& Bentler, P. M. (2010). Ensuring Positiveness of the Scaled Difference Chisquare Test Statistic. Psychometrika, 75(2), 243-248. https://doi.org/10.1007/s11336-009-9135-y

Schafer, J., \& Graham, J. (2002). Missing data: our view of the state of the art. Psychological Methods, 7(2), 147-177. https://doi.org/10.1037//1082-989X.7.2.147

Schröder, M. (2017). Is income inequality related to tolerance for inequality? Social Justice Research, 30, 23-47. https://doi.org/10.1007/s11211-016-0276-8

Senik, C. (2009). Direct evidence on income comparisons and their welfare effects. Journal of Economic Behavior \& Organization, 72, 408-424. https://doi.org/10.1016/j.jebo.2009.04.019

Somma, M., Bargsted, M., Disi Pavlic, R., \& Medel, R. (2020). No water in the oasis: the Chilean spring of 2019-2020. Social Movement Studies, https://doi.org/10.1080/14742837.2020.1727737 
Son Hing, L., Wilson, A., Gourevitch, P., English, J., \& Sin, P. (2019). Failure to respond to rising income inequality: processes that legitimize growing disparities. Daedalus, 148(3), 105-135. https://doi.org/10.1162/daed_a_01752

Son, J., \& Lin, N. (2012). Network diversity, contact diversity, and status attainment. Social Networks, 34(4), 670-681. https://doi.org/10.1016/j.socnet.2012.06.006

Swank, J., \& Mullen, P. (2017). Evaluating evidence for conceptually related constructs using bivariate correlations. Measurement and Evaluation in Counseling and Development, 50(4), 270-274. https://doi.org/10.1080/07481756.2017.1339562

Usami, S., Murayama, K., \& Hamaker, H. (2019). A unified framework of longitudinal models to examine reciprocal relations. Psychological Methods, 24(5), 637-657. http://dx.doi.org/10.1037/met0000210

Wilkinson, R., \& Pickett, K. (2017). The enemy between us: The psychological and social costs of inequality. European Journal of Social Psychology, 47, 11-24. https://doi.org/10.1002/ejsp.2275

Wiwad, D., Mercier, B., Maraun, M., Robinson, A., Piff, P., Aknin, L., \& Shariff, A. (2019). The support for economic inequality scale: Development and adjudication. PloS ONE, 14(6), 1-29. https://doi.org/10.1371/journal.pone.0218685

Wolf, E., Harrington, K., Clark, S., \& Miller, M. (2013). Sample size requirements for structural equation models: an evaluation of power, bias, and solution propriety. Educational and Psychological Measurement, 76(6), 913-934. https://doi.org/10.1177/0013164413495237

Wothke, W. (2000). Longitudinal and multigroup modeling with missing data. In T. D. Little, K. U. Schnabel, \& J. Baumert (Eds.), Modeling longitudinal and multilevel data: 
Practical issues, applied approaches, and specific examples (pp. 219-240, 269-281).

Lawrence Erlbaum Associates Publisher

T1

$\mathrm{T} 2$

T3

T4

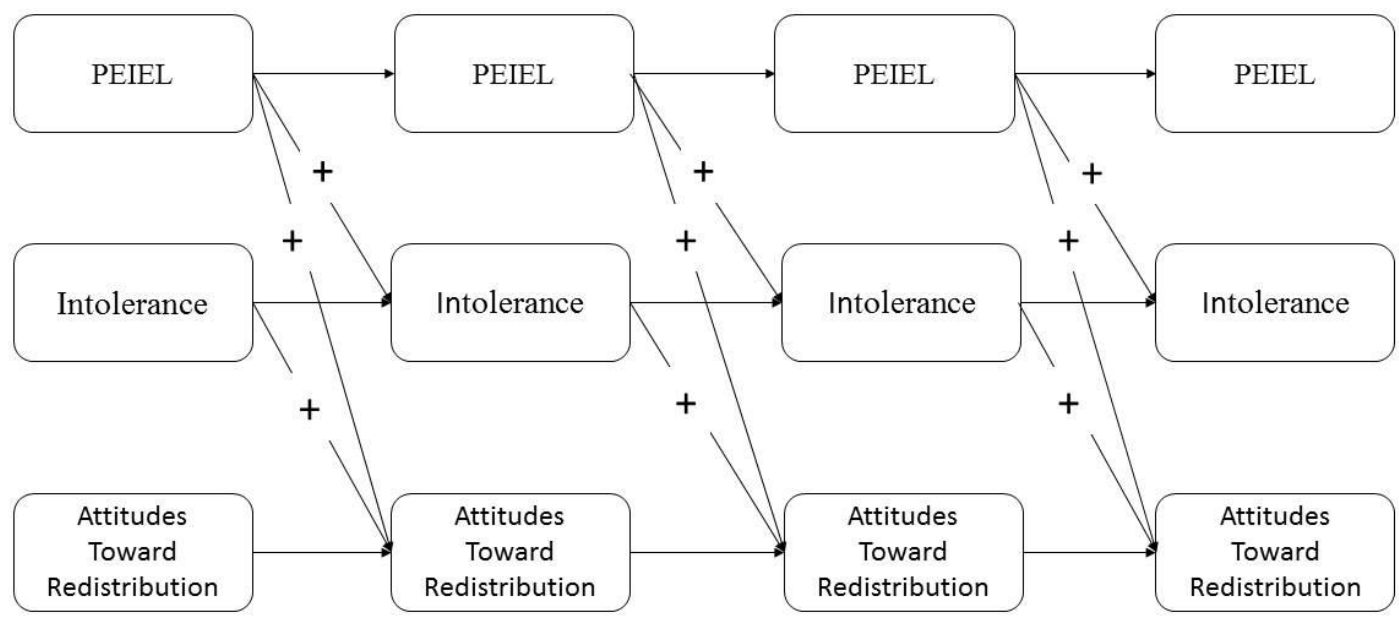

Figure 1. Model tested in the current study. 


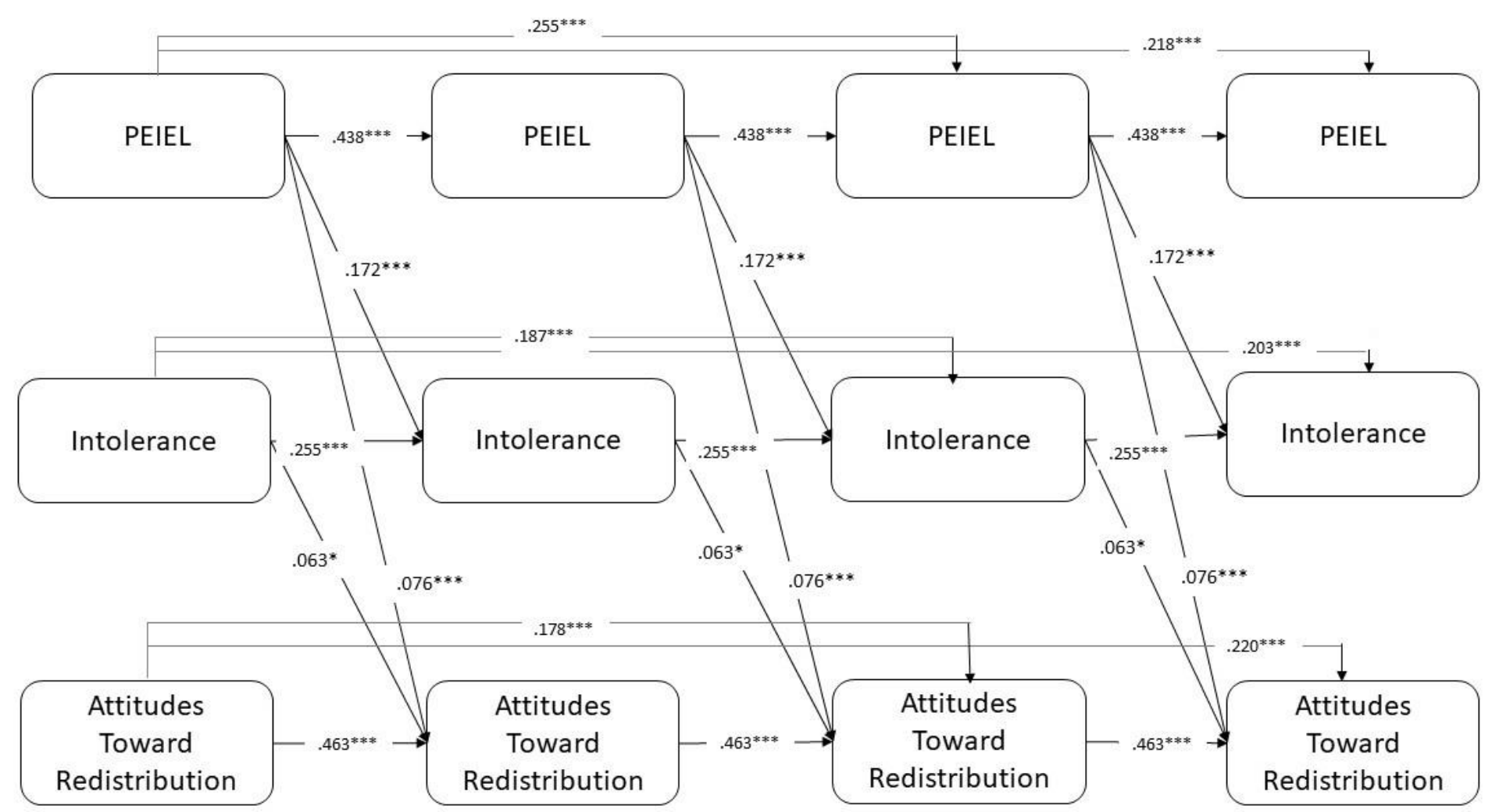

Figure 2. Full longitudinal constrained forward model for perceived economic inequality in everyday life tested in the current study.

Note. ${ }^{* * *} p<.001,{ }^{* *} p<.01,{ }^{*} p<.05$. Model $2 \mathrm{~b}$ in Table $2: \chi 2(78)=352.219 ; p<.001$; CFI $=.944$; RMSEA $=.059$; SRMR $=.085$. Unstandardized coefficients are reported. Within-time covariates were all significant at time point 1 . For parsimonious reasons, full details can be seen in the supplemental materials Table S1. 


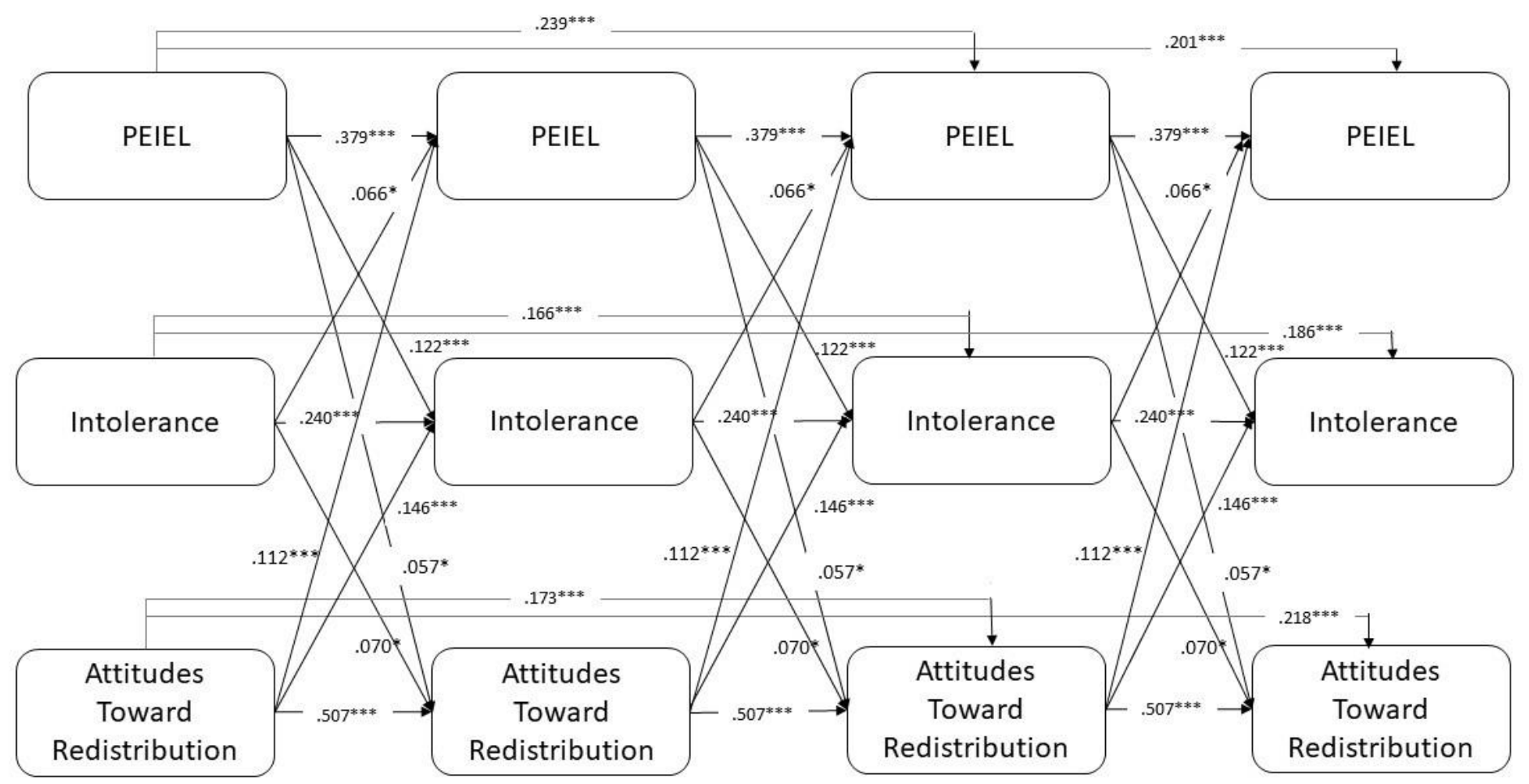

Figure 3. Full longitudinal constrained bidirectional model tested in the current study.

Note. $* * * p<.001, * * p<.01, * p<.05$. Model $4 \mathrm{~b}$ in Table $2: \chi^{2}(72)=253.704 ; p<.001 ;$ CFI $=.963 ;$ RMSEA $=.050 ;$ SRMR $=.050$. Unstandardized coefficients are reported. Within-time covariates were all significant at time point 1 . For parsimonious reasons, full details can be seen in the supplemental materials Table S2. 
Table 1

Descriptive statistics and correlations of the measures included in the current study

\begin{tabular}{ccccccccc}
\hline & Items & Range & $M$ & \multicolumn{2}{c}{$95 \%$ CI } & $r_{T 1-T 2}$ & $r_{T 2-T 3}$ & $r_{T 3-T 4}$ \\
& & & & $\begin{array}{c}\text { Lower } \\
\text { Limit }\end{array}$ & $\begin{array}{c}\text { Upper } \\
\text { Limit }\end{array}$ & & & \\
\hline PEIEL & & & & & & & & \\
$T_{1}$ & 1 & $1.00-5.00$ & 4.33 & 4.28 & 4.38 & $.50^{* *}$ & $.50^{* *}$ & $.53^{* *}$ \\
$T_{2}$ & 1 & $1.00-5.00$ & 4.29 & 4.24 & 4.34 & & & \\
$T_{3}$ & 1 & $1.00-5.00$ & 4.28 & 4.23 & 4.34 & & & \\
$T_{4}$ & 1 & $1.00-5.00$ & 4.27 & 4.21 & 4.33 & & &
\end{tabular}

Tolerance to Inequality

$\begin{array}{lllllllll}T_{1} & 1 & 1.00-5.00 & 4.64 & 4.59 & 4.68 & .36^{* *} & .43^{* *} & .41^{* *} \\ T_{2} & 1 & 1.00-5.00 & 4.63 & 4.59 & 4.67 & & & \\ T_{3} & 1 & 1.00-5.00 & 4.60 & 4.55 & 4.64 & & \\ T_{4} & 1 & 1.00-5.00 & 4.58 & 4.52 & 4.63 & & \end{array}$

Attitudes toward redistribution

$\begin{array}{lllllllll}T_{1} & 2 & 1.00-5.00 & 4.02 & 3.96 & 4.08 & .60 * * & .61 * * & .62 * * \\ T_{2} & 2 & 1.00-5.00 & 4.01 & 3.96 & 4.07 & & \\ T_{3} & 2 & 1.00-5.00 & 4.02 & 3.96 & 4.08 & & \\ T_{4} & 2 & 1.00-5.00 & 4.02 & 3.96 & 4.09 & & \end{array}$

Household Income

\begin{tabular}{lllllllll}
$T_{1}$ & 1 & $1.00-22.00$ & 10.99 & 10.52 & 11.46 & $.84 * * *$ & $.83^{* * *}$ & $.81^{* * *}$ \\
$T_{2}$ & 1 & $1.00-22.00$ & 11.29 & 10.83 & 11.75 & & & \\
$T_{3}$ & 1 & $1.00-22.00$ & 11.39 & 10.92 & 11.85 & & & \\
$T_{4}$ & 1 & $1.00-22.00$ & 11.61 & 11.14 & 12.07 & & & \\
\hline
\end{tabular}

Note. $* p<.05, * * p<.01, * * * p<.001$ 
Table 2

Variable's correlation matrix measured at the same time point

\begin{tabular}{|c|c|c|c|c|}
\hline & 1 & 2 & 3 & 4 \\
\hline \multicolumn{5}{|l|}{$T 1$} \\
\hline PEIEL & 1 & $.38 * * *$ & $.35 * * *$ & $-.12 * * *$ \\
\hline Intolerance of inequality & & 1 & $.40 * * *$ & $-.08 *$ \\
\hline Attitudes toward redistribution & & & 1 & $-.20 * * *$ \\
\hline Household income & & & & 1 \\
\hline \multicolumn{5}{|l|}{$T 2$} \\
\hline PEIEL & 1 & $.46 * * *$ & $.38 * * *$ & $-.18 * * *$ \\
\hline Intolerance of inequality & & 1 & $.37 * * *$ & $-.09 * *$ \\
\hline Attitudes toward redistribution & & & 1 & $-.21 * * *$ \\
\hline Household income & & & & 1 \\
\hline \multicolumn{5}{|l|}{$T 3$} \\
\hline PEIEL & 1 & $.53 * * *$ & $.39 * * *$ & $-.18 * * *$ \\
\hline Intolerance of inequality & & 1 & $.43 * * *$ & $-.11 * *$ \\
\hline Attitudes toward redistribution & & & 1 & $-.13 * * *$ \\
\hline Household income & & & & 1 \\
\hline \multicolumn{5}{|l|}{$T 4$} \\
\hline PEIEL & 1 & $.49 * * *$ & $.40 * * *$ & $-.13 * * *$ \\
\hline Intolerance of inequality & & 1 & $.40 * * *$ & -.04 \\
\hline Attitudes toward redistribution & & & 1 & $-.09 * *$ \\
\hline Household income & & & & 1 \\
\hline
\end{tabular}

Note. ${ }^{* * *} p<.001, * * p<.01, * p<.05$ 
Table 3

Comparisons of autoregressive, unidirectional forward, unidirectional reverse and bidirectional longitudinal models tested in the current study

\begin{tabular}{|c|c|c|c|}
\hline Model & Model Fit & Model Comparison & Model Invariance Testing \\
\hline $1 \mathrm{a}$ & $\chi^{2}(85)=749.450 ; p<.001 ;$ CFI $=.864 ;$ RMSEA $=.088 ;$ SRMR $=.157$ & & \\
\hline $1 b$ & $\chi^{2}(93)=752.161 ; p<.001 ;$ CFI $=.865 ;$ RMSEA $=.084 ;$ SRMR $=.160$ & $1 \mathrm{~b}$ vs. $1 \mathrm{a}$ & $\Delta \mathrm{CFI}=.001 ; \Delta \mathrm{RMSEA}=-.004$ \\
\hline \multirow[t]{2}{*}{$2 b$} & $\chi^{2}(78)=352.219 ; p<.001 ;$ CFI $=.944 ;$ RMSEA $=.059 ;$ SRMR $=.085$ & $2 \mathrm{~b}$ vs. $2 \mathrm{a}$ & $\Delta \mathrm{CFI}=-.015 ; \Delta \mathrm{RMSEA}=.000$ \\
\hline & & $2 \mathrm{~b}$ vs. $1 \mathrm{~b}$ & $\Delta \mathrm{CFI}=.079 ; \Delta \mathrm{RMSEA}=-.025$ \\
\hline \multirow{2}{*}{$3 b$} & & $3 b$ vs. $1 b$ & $\Delta \mathrm{CFI}=.085 ; \Delta \mathrm{RMSEA}=-.028$ \\
\hline & & $3 b$ vs. $2 b$ & $\Delta \mathrm{CFI}=.006 ; \Delta \mathrm{RMSEA}=-.003$ \\
\hline $4 a$ & $\chi^{2}(40)=150.755 ; p<.001 ;$ CFI $=.977 ;$ RMSEA $=.053 ;$ SRMR $=.029$ & & \\
\hline \multirow[t]{2}{*}{$4 b$} & $\chi^{2}(72)=253.704 ; p<.001 ;$ CFI $=.963 ;$ RMSEA $=.050 ;$ SRMR $=.050$ & $4 \mathrm{~b}$ vs. $4 \mathrm{a}$ & $\Delta \mathrm{CFI}=-.014 ; \Delta \mathrm{RMSEA}=-.003$ \\
\hline & & $4 \mathrm{~b}$ vs. $1 \mathrm{~b}$ & $\Delta \mathrm{CFI}=.098 ; \Delta \mathrm{RMSEA}=-.034$ \\
\hline
\end{tabular}

Note. CFI = comparative fit index; RMSEA = root-mean-square error of approximation; SRMR = standardized root-mean-square residual; 1a $=$ autoregressive model (freely estimated parameters); $1 \mathrm{~b}=$ autoregressive model (within construct path equivalence); $2 \mathrm{a}=$ unidirectional forward model: predictor $\rightarrow$ mediators $\rightarrow$ outcomes (freely estimated parameters); $2 \mathrm{~b}=$ unidirectional forward model (within construct path equivalence);

$3 \mathrm{a}=$ unidirectional backward model: outcomes $\rightarrow$ mediators $\rightarrow$ predictor (freely estimated parameters); $3 \mathrm{~b}=$ unidirectional backward model (within construct path equivalence); $4 \mathrm{a}=$ bidirectional model (freely estimated parameters); $4 \mathrm{~b}=$ bidirectional model (within construct path equivalence for new paths). 


\section{PERCEIVED ECONOMIC INEQUALITY IN EVERYDAY LIFE}

Table 4

Significance of the mediation effects tested in the current study

\begin{tabular}{|c|c|c|c|c|c|c|c|c|}
\hline & \multirow[t]{2}{*}{$T_{1}$} & \multirow[t]{2}{*}{$T_{2}$} & \multirow[t]{2}{*}{$T_{3}$} & \multirow[t]{2}{*}{$\mathrm{T}_{4}$} & \multirow{2}{*}{$\begin{array}{l}\text { Size of Indirect } \\
\text { Effect }(\beta)\end{array}$} & \multirow{2}{*}{$\begin{array}{l}p \text {-value of } \\
\text { Effects }\end{array}$} & \multicolumn{2}{|c|}{ 95\% C.I. } \\
\hline & & & & & & & Lower & Upper \\
\hline $\begin{array}{c}\text { Forward Model } \\
\text { (2b) }\end{array}$ & & & & & & & & \\
\hline Indirect effect & PEIEL & Intolerance & ATR & - & .011 & .021 & .006 & .016 \\
\hline Indirect effect & - & PEIEL & Intolerance & ATR & .011 & .021 & .006 & .016 \\
\hline $\begin{array}{c}\text { Reverse } \\
\text { Model (3b) }\end{array}$ & & & & & & & & \\
\hline Indirect effect & ATR & Intolerance & PEIEL & - & .012 & .013 & .007 & .017 \\
\hline Indirect effect & - & ATR & Intolerance & PEIEL & .012 & .013 & .007 & .017 \\
\hline $\begin{array}{c}\text { Bidirectional } \\
\text { Model (4b) }\end{array}$ & & & & & & & & \\
\hline Indirect effect & PEIEL & Intolerance & ATR & - & .008 & .024 & .004 & .012 \\
\hline Indirect effect & - & PEIEL & Intolerance & ATR & .008 & .024 & .004 & .012 \\
\hline Indirect effect & ATR & Intolerance & PEIEL & - & .010 & .019 & .006 & .014 \\
\hline Indirect effect & - & ATR & Intolerance & PEIEL & .010 & .019 & .006 & .014 \\
\hline
\end{tabular}

Note. Unstandardized coefficients. $p$ values are two tails. Explanation of the abbreviations: PEIEL= Perceived Economic Inequality in Everyday Life; ATR=Attitudes Towards Redistribution. 